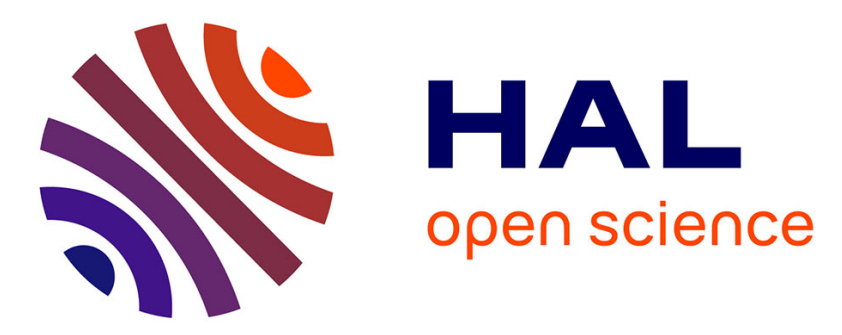

\title{
Gas-Phase reactivity of lead(II) Ions with D-Glucose. Combined Electrospray Ionization Mass Spectrometry and Theoretical Study
}

Jean-Yves Salpin, Jeanine Tortajada

\section{- To cite this version:}

Jean-Yves Salpin, Jeanine Tortajada. Gas-Phase reactivity of lead(II) Ions with D-Glucose. Combined Electrospray Ionization Mass Spectrometry and Theoretical Study. Journal of Physical Chemistry A, 2003, 107 (16), pp.2943-2953. 10.1021/jp022553x . hal-00068555

\section{HAL Id: hal-00068555 https://hal.science/hal-00068555}

Submitted on 4 Oct 2018

HAL is a multi-disciplinary open access archive for the deposit and dissemination of scientific research documents, whether they are published or not. The documents may come from teaching and research institutions in France or abroad, or from public or private research centers.
L'archive ouverte pluridisciplinaire HAL, est destinée au dépôt et à la diffusion de documents scientifiques de niveau recherche, publiés ou non, émanant des établissements d'enseignement et de recherche français ou étrangers, des laboratoires publics ou privés. 


\title{
Gas-phase reactivity of Lead(II) ions with D-glucose. A combined electrospray ionization mass spectrometry and theoretical study.
}

\author{
Jean-Yves Salpin and Jeanine Tortajada \\ Laboratoire Analyse et Environnement, UMR 8587, Bâtiment des Sciences, Université \\ d'Evry Val d'Essonne, Boulevard François Mitterrand, 91025 EVRY CEDEX, France.
}

Corresponding author: Jean-Yves Salpin

Tel: 33169477647 Fax: 33169477655

e-mail : Jean-Yves.Salpin@ chimie.univ-evry.fr

Number of pages (including Table and Figure legends) : 24

\begin{abstract}
The gas-phase reactivity of lead(II) ions towards D-glucose has been studied by means of mass spectrometry and theoretical calculations. Electrospray mass spectra show that this reactivity mainly gives rise to $\left[\mathrm{Pb}(\mathrm{D} \text {-glucose })_{\mathrm{m}}-\mathrm{H}\right]^{+}$species $(\mathrm{m}=1,2)$. These ions are obtained by dissociative proton transfer within the doubly charged complexes, $\left[\mathrm{Pb}(\mathrm{D} \text {-glucose })_{n}\right]^{2+}$ complexes $(\mathrm{n}=2-12)$, observed in significant abundance at low cone voltage. Low-energy MS/MS experiments on $[\mathrm{Pb}(\mathrm{D} \text {-glucose })-\mathrm{H}]^{+}(\mathrm{m} / \mathrm{z}$ 387) show that this ion essentially dissociates according to cross-ring cleavages leading mainly to the elimination of $\mathrm{C}_{2} \mathrm{H}_{4} \mathrm{O}_{2}$ and $\mathrm{C}_{4} \mathrm{H}_{8} \mathrm{O}_{4}$ neutrals, and to a minor extent in the loss of $\mathrm{C}_{3} \mathrm{H}_{6} \mathrm{O}_{3}$. Use of labeled D-glucose demonstrates that the former implies specifically the elimination of $\mathrm{C}(1)$ and $\mathrm{C}(2)$ stereocenters, whereas the latter corresponds to at least two distinct fragmentations. This finding clearly suggests that several $[\mathrm{Pb}(\mathrm{D} \text {-glucose })-\mathrm{H}]^{+}$structures, characterized by different coordination schemes, coexist in the gas-phase. This is confirmed by the density functional theory study carried out on both anomers, since the various coordination sites on the pyranose are close in energy. The most favorable $\mathrm{Pb}^{2+} / \mathrm{D}$-glucopyranose association is characterized by the metallic center bonded to the deprotonated hydroxymethyl group and interacting with the hemiacetal oxygen. In such a position, the $\mathrm{Pb}^{2+}$ ion catalyses the ring-opening process by activation of the two $\mathrm{C}-\mathrm{O}$ ring bonds. This not only accounts for the fragmentation observed upon collision, but also suggests that beside fragmentation, pyranosic complexes may evolve towards energetically favored acyclic structures.
\end{abstract}




\section{Introduction}

From the beginning of the $18^{\text {th }}$ century to the early 1990 's, anthropogenic emission of lead has dramatically grown, mainly due to the massive use of alkyllead species as antiknock agents in gasoline, and to the production of $\mathrm{Pb}$ acid storage batteries or leaded paints. ${ }^{1,2}$ Both organic and inorganic lead are now ubiquitous in the environment, even though, because of the sudden awareness of its toxicity, many countries have significantly reduced during the last decade the use of this metal in numerous industrial fields. These species may indeed cause severe damage to human health. For instance, it has been established that alkylleads are rapidly metabolized and readily cross the blood-brain barrier. These physicochemical properties makes the central nervous system the main site of their toxic action. However, lead can also affect almost every organ and system in the human body, such as the liver, kidneys or heart. Lead is also known to cause weakness of joints and anemia. Since lead readily crosses the placenta, the fetus is at risk. Finally, alkyllead compounds decompose in aqueous solution to give in a final step $\mathrm{Pb}^{2+}$ ions ${ }^{3}$, a large-scale environmental pollutant, which is known to obstruct heme biosynthesis, to inhibit several zinc enzymes, and to interact with nucleic acids and transfer RNA, affecting protein synthesis. ${ }^{4}$

The bioavailability and toxicity of metals in the environment are governed by the ability of natural organic molecules to bind metal ions. Among these molecules carbohydrates are the most abundant. They are mainly found as polysaccharides that are essential for both plant and animal life. These macromolecules may be easily converted to a large variety of monosaccharides, which, in turn, may complex metal ions due to their numerous hydroxyl groups. Complexing of carbohydrates with metal ions, and more particularly with $\mathrm{Ca}^{2+}$ cations, has been widely studied in solution ${ }^{5,6}$, because of the involvement of metal ionsaccharide interactions in key biological processes. On the other hand, studies concerning the interactions of $\mathrm{Pb}^{2+}$ ions with saccharides in aqueous media are scarce and generally concern determination of thermochemical parameters such as stability constants or heats of 
reaction. ${ }^{7,8,9,10}$ The intimate mechanism of interaction is not well characterized. Moreover, these complexation processes depend on many parameters of aqueous media, such as $\mathrm{pH}$, ionic strength or metal/ligand ratio. So, in order to properly assess the influence of each of these parameters, it is of particular interest to describe in a first step the gas-phase reactivity of metallic cations. Our previous studies have demonstrated that the gas-phase reactivity of $\mathrm{Pb}^{2+}$ ions allows isomeric hexoses and pentoses to be characterized ${ }^{11,12,13}$, thus underlining the influence of the arrangement of the various hydroxyl groups on the complexation process. The present work aims to explore the mechanical aspects of the gas-phase interaction between $\mathrm{Pb}^{2+}$ ions and the most abundant monosaccharide, D-glucose (Scheme 1). For this purpose, we combined mass spectrometry experiments, notably on deoxy- and labeled species, with theoretical calculations.

\section{$<$ Scheme 1>}

\section{Experimental}

Electrospray mass spectra were recorded on an Applied Biosystems/MDS Sciex API2000 triple-quadrupole instrument fitted with a "turboionspray" ion source. Samples were introduced in the source using direct infusion with a syringe pump, at a flow rate of $5 \mu \mathrm{l} / \mathrm{min}$. Ionization of the samples was achieved by applying a voltage of $5.5 \mathrm{kVolts}$ on the sprayer probe and by the use of a nebulizing gas (GAS1, air) surrounding the sprayer probe, intersected by a heated gas (GAS2, air) at an angle of approximately $90^{\circ}$. The operating pressure of these two gases were typically 1.4 and 2.1 bars, respectively, and the temperature of GAS2 was set at $100^{\circ} \mathrm{C}$. The curtain gas $\left(\mathrm{N}_{2}\right)$, which prevents air or solvent from entering the analyser region, was adjusted to a pressure of 2.1 bars. As detailed in the following sections, the declustering potential (DP), defined as the difference of potentials between the orifice plate and the skimmer, was fixed to 20 Volts to perform both MS and MS/MS experiments. 
MS/MS spectra were carried out by introducing nitrogen as collision gas in the second quadrupole at a total pressure of $4 \times 10^{-5}$ mbar, the background pressure being around $10^{-5}$ mbar. Furthermore, MS/MS spectra were systematically recorded at different collision energies (the collision energy is given by the difference of potentials between the focusing quadrupole Q0 preceding Q1, and the collision cell Q2).

All the measurements presented thereafter were carried out in $100 \%$ water purified with a Milli-Q water purification system. Lead nitrate was chosen to generate $\mathrm{Pb}^{2+}$ ions because of its high solubility in water. All the monosaccharides were dissolved in water without any preliminary derivatization. The resulting $\mathrm{pH}$ of our aqueous mixtures of lead nitrate/D-glucose $\left(5 \times 10^{-5} \mathrm{~mol} . \mathrm{L}^{-1} / 10^{-4} \mathrm{~mol} . \mathrm{L}^{-1}\right)$ is about 5 , similar to that of Milli-Q water.

Metallic salt, D-glucose and deoxy-D-glucoses are commercially available from Aldrich and Fluka (Saint-Quentin Fallavier, France) and were used without any further purification. ${ }^{13} \mathrm{C}$ and deuterium labeled D-glucoses were obtained from Omicron Biochemicals (South Bend, Indiana, USA).

\section{Computational details}

Due to the large number of atoms involved in the complexes studied, molecular orbital calculations have been undertaken using the B3LYP density functional approach, as implemented in the Gaussian-98 set of programs. ${ }^{14}$ This method combines Becke's threeparameter non local hybrid exchange potential ${ }^{15}$ with the non local correlation function of Lee, Yang and Parr. ${ }^{16}$ This formalism has been found well suited both for description of ionmolecule complexes ${ }^{17,18,19}$ and for the study of inter- and intra-molecular hydrogen bonds. 19,20,21,22 The different structures have first been optimized with the dp-polarized 6-31G(d,p) basis set for $\mathrm{C}, \mathrm{H}$ and $\mathrm{O}$ atoms. Harmonic vibrational frequencies have been determined at that level. Finally, relative energies were determined using the extended basis set 6-311+G(2df,2p). 
Different effective core potentials have been proposed in the literature for $\mathrm{Pb}$. In the present study, we used the "Stuttgart" quasi-relativistic pseudo-potential developed by Küchle et al. ${ }^{23}$ This particular ECP employs a $(4 s, 4 p, 1 d) /[2 s, 2 p, 1 d]$ basis set with a $(3,1)$ contraction scheme for $s$ and $p$ functions. Hence, this basis set can be used directly in conjunction with the standard

6-31G(d,p) Pople basis set of $\mathrm{C}, \mathrm{O}$ and $\mathrm{H}$, for geometry optimization. To perform calculations at a higher level of theory, we have uncontracted the original scheme of the Stuttgart basis set to obtain a triple-zeta like basis set, with a $(2,1,1)$ contraction scheme for $s$ and $p$ functions. Furthermore this basis set was supplemented with one $d$ and one $f$ polarization functions $\left(\alpha_{d}=\right.$ 0.195, $\left.\alpha_{f}=0.375\right)$ and a $s p$ diffuse function $\left(\alpha_{s p}=0.033\right) .{ }^{24}$ To create a multiple set of $d$ functions from a single optimized function, we have followed the procedure previously described by González et $a l^{25}$, in which the new exponents are obtained as multiples, $n \alpha_{d}$, or fractions, $\alpha_{d} / n$, of the single exponent $\alpha_{d}$, with $\mathrm{n}=1.5$. This modified basis set has been used together with the $\mathrm{C}, \mathrm{H}$ and $\mathrm{O} 6-311+\mathrm{G}(2 \mathrm{df}, 2 \mathrm{p})$ basis set for single point calculations. For simplicity in nomenclature, the basis sets used for $\mathrm{Pb}$ in conjunction with the 6-31G(d,p) and $6-311+\mathrm{G}(2 \mathrm{df}, 2 \mathrm{p})$ for the remaining atoms, will now be referred to as 6-31G(d,p) and 6-311+G(2df,2p) basis sets respectively.

Throughout this paper total energies are expressed in hartree and relative energies in $\mathrm{kJ} / \mathrm{mol}$. Unless otherwise noted, the relative energies given hereafter are those obtained at a level equivalent to B3LYP/6-311+G(2df,2p)//B3LYP/6-31G(d,p)+ZPE. Detailed geometries of all the structures mentioned in this paper are available as supporting information (S1).

\section{Results}

Positive ion electrospray spectra of cationized glucose. Figure 1 presents the $\mathrm{m} / \mathrm{z}$ 200-1200 range of the electrospray mass spectrum obtained at a declustering potential of 20 Volts, when infusing an aqueous lead nitrate/D-Glucose mixture $\left(5 \times 10^{-5} \mathrm{~mol} . \mathrm{L}^{-1} / 5 \times 10^{-4} \mathrm{~mol} . \mathrm{L}^{-1}\right)$. Lead has four isotopes with the natural abundances: $1.4 \%{ }^{204} \mathrm{~Pb} / 24.1 \%{ }^{206} \mathrm{~Pb} / 22.1 \%{ }^{207} \mathrm{~Pb} / 52.4 \%$ 
${ }^{208} \mathrm{~Pb}$. Because of this specific isotopic distribution (Figure 1), peaks involving one lead atom correspond to characteristic triplets on the spectra and are easily identified (to simplify, we shall not consider the very weak ${ }^{204} \mathrm{~Pb}$ contribution). Unless otherwise noted, throughout this article the $\mathrm{m} / \mathrm{z}$ of any metal-containing ion will always refer to the one containing the metal isotope of highest natural abundance $\left({ }^{208} \mathrm{~Pb}\right)$. From Figure 1, we can see that the electrospray spectrum, at $\mathrm{DP}=20$ Volts, presents hydrated lead hydroxide ions $\mathrm{PbOH}^{+} \cdot \mathrm{xH}_{2} \mathrm{O}(\mathrm{x}=0-4 \mathrm{at} \mathrm{m} / \mathrm{z}$ 225, 243, 261279 and 297). Low-energy CID spectra of these hydrated hydroxide ions are characterized by loss of one or several molecules of water. Elimination of $\mathrm{OH}$ is never observed, suggesting that the binding energy of $\mathrm{OH}$ is greater than that of water, as already observed for transition metals such as $\mathrm{Mn}$, $\mathrm{Co}, \mathrm{Ni}$ or $\mathrm{Zn}^{26}$ Increasing the declustering potential up to 200 Volts results in the gradual removal of hydrated hydroxide ions. Conversely, bare lead ion $\mathrm{Pb}^{+}(\mathrm{m} / \mathrm{z} 208)$, originating from $\mathrm{PbOH}^{+}$by loss of a hydroxyl radical, starts to appear at $\mathrm{DP}=50$ Volts, to become the base peak at the highest DP.

Numerous studies have shown that electrospray ionization can be used to generate hydrated divalent metal ions $\mathrm{M}\left(\mathrm{H}_{2} \mathrm{O}\right)_{\mathrm{n}}{ }^{2+27,28,29,30,31,32,33}$ Furthermore, these ions may easily dissociate either by water loss or by formation of metal hydroxide ions according to the following dissociative proton transfer reaction (equation 1):

$$
\mathrm{M}\left(\mathrm{H}_{2} \mathrm{O}\right)_{\mathrm{n}}^{2+} \longrightarrow \mathrm{MOH}\left(\mathrm{H}_{2} \mathrm{O}\right)_{\mathrm{n}-\mathrm{k}-2}^{+}+\mathrm{H}_{3} \mathrm{O}^{+}\left(\mathrm{H}_{2} \mathrm{O}\right)_{\mathrm{k}}
$$

The second ionization potential of the metal $\left(\mathrm{IP}_{2}\right)$ has been proposed as one of the determining factors for both the formation of hydrated metals and their fragmentation according to this proton transfer reaction. ${ }^{27-29}$ However, in a recent paper, Williams and co-workers deduced from their experiments that its influence was only indirect ${ }^{32}$, and put forward the key role of the ionic radius. ${ }^{32,34}$ Hence, metal hydroxide formation is particularly favorable as the size of the metal ion decreases. In the present study, we did not detect any $\mathrm{Pb}\left(\mathrm{H}_{2} \mathrm{O}\right)_{\mathrm{n}}{ }^{2+}$ ions, but only $\mathrm{PbOH}\left(\mathrm{H}_{2} \mathrm{O}\right)_{\mathrm{n}}{ }^{+}$ions $(\mathrm{n}=1-4)$ species. This is quite striking since lead has the same $\mathrm{IP}_{2}$ as Magnesium $\left(\mathrm{IP}_{2}(\mathrm{~Pb})=15.03 \mathrm{eV}^{35}\right)$, and similar ionic radius as Strontium ${ }^{35}$ 
(whatever the coordination number considered), two metals for which hydrated metal ions are easily obtained under electrospray conditions.

On the other hand, as Kebarle and co-workers noticed, the proton transfer reaction (equation 1) is also facilitated by collisions between the hydrated metal and gas molecules in the interface region. ${ }^{27-29} \mathrm{We}$ tried to record spectra with the mildest source/interface conditions $(\mathrm{DP}=0$ Volt, low curtain and heated gases) but again failed in detecting any hydrated lead ions. A possible explanation could involve the composition of the aqueous solution of lead nitrate. For instance, Shvarstburg et al. did not manage to produce $\mathrm{Sn}\left(\mathrm{H}_{2} \mathrm{O}\right)_{\mathrm{n}}{ }^{2+}$ ions by electrospray, and deduced from equilibrium calculations that this was not so surprising since $\mathrm{SnOH}^{+}$ions should represent $99.4 \%$ of the ionic species in a $2 \mathrm{mM}$ solution. ${ }^{36}$ The $\mathrm{pH}$ of our lead nitrate solutions, when using milli-Q water, ranges from 3 to 5 , for $\mathrm{Pb}\left(\mathrm{NO}_{3}\right)_{2}$ concentrations spanning from $10^{-3} \mathrm{~mol} . \mathrm{L}^{-1}$ to $10^{-5} \mathrm{~mol} . \mathrm{L}^{-1}$. According to a recent potentiometric study ${ }^{37}, \mathrm{~Pb}^{2+}$ ions are the predominant ionic species at $\mathrm{pH} \leq 5$ for those concentrations. Consequently the lack of $\mathrm{Pb}\left(\mathrm{H}_{2} \mathrm{O}\right)_{\mathrm{n}}{ }^{2+}$ ions cannot be attributed to the properties of the aqueous solution.

In a recent paper, Stace and co-workers used the pick-up method to generate gas-phase $\mathrm{Pb}(\mathrm{ROH})_{\mathrm{n}}{ }^{2+}$ ions. ${ }^{38}$ They also failed to detect any $\mathrm{Pb}\left(\mathrm{H}_{2} \mathrm{O}\right)_{\mathrm{n}}{ }^{2+}$ ions but managed to observe doubly charged species with propan-1-ol and butan-1-ol. These experiments, complemented by DFT calculations, allowed them to deduce that the stability of $\mathrm{Pb}(\mathrm{ROH})_{4}{ }^{2+}$ could be explained by the hard-soft acid-base (HSAB) concept. ${ }^{39}$ Increasing the length of the alkyl chain indeed results in the softening of the base, a decrease in the ionic character of the $\mathrm{Pb}-\mathrm{O}$ bond, and a greater stabilization of $\mathrm{Pb}(\mathrm{ROH})_{4}{ }^{2+}$ ions. Our results, though obtained by a different ionization technique, confirm these findings. While no doubly charged ions are observed with water, the contrary is the case with D-glucose, a highly polarizable (soft) base, where we observe a series of $\left[\mathrm{Pb}(\mathrm{D}-\text { glucose })_{\mathrm{n}}\right]^{2+}$ ions $(\mathrm{n}=2-12, \mathrm{~m} / \mathrm{z} 284,374,464,554,644$, $734,824,914,1004,1094$ and 1184), in spite of the great excess of water (Figure 1). The 
detection of these doubly charged species further confirms the presence of $\mathrm{Pb}^{2+}$ ions in the aqueous solution. Interaction between lead(II) ions and D-glucose also results in ions of general formula $\left[\mathrm{Pb}(\mathrm{D} \text {-glucose })_{\mathrm{m}}-\mathrm{H}\right]^{+}(\mathrm{m}=1,3)$ (Figure 1), at $\mathrm{m} / \mathrm{z} 387$ and 567 and 747 . This double reactivity has been already observed for alkaline earth cations ${ }^{40}$ and iron. $^{41} \mathrm{We}$ optimized the yield of formation of cationized species as previously reported. ${ }^{13}$ The highest ionization yield is obtained for a metal/D-glucose ratio of $1 / 2\left(5 \times 10^{-5} \mathrm{~mol} . \mathrm{L}^{-1} / 10^{-4} \mathrm{~mol} . \mathrm{L}^{-1}\right)$ and a declustering potential of 20 Volts. Whatever the ratio considered, $\left[\mathrm{Pb}(\text { monosaccharide })_{\mathrm{m}}-\mathrm{H}\right]^{+}$ions are predominant and $\mathrm{m} / \mathrm{z} 387(\mathrm{~m}=1)$ is always the most abundant complex observed. Nevertheless, the metal/monosaccharide ratio has a significant influence on the detection of the doubly charged species, since we only observed six $\left[\mathrm{Pb}(\mathrm{D} \text {-glucose })_{\mathrm{n}}\right]^{2+}$ ions $(\mathrm{n}=2-7)$ for the stoichiometry $1 / 2$. Therefore, the metal:monosaccharide ratio influences the relative abundance of these two series, but the effect is not as spectacular as for $\mathrm{Ca}^{2+}$ ions. ${ }^{40}$

We tried to characterize the structure of these doubly charged species by recording the lowenergy CID spectra of $\mathrm{m} / \mathrm{z} 284,374,464,554,644$ ions (for a metal/sugar ratio of $1 / 5$ ). The results are summarized in Table 1. These species exhibit the same behavior upon collision as $\mathrm{M}\left(\mathrm{H}_{2} \mathrm{O}\right)_{\mathrm{n}}{ }^{2+}$ ions. Two main dissociation channels are indeed observed :

(i) elimination of one or several glucose units leading to doubly charged ions,

(ii) proton transfer within the complex, giving rise to $\left[\mathrm{Pb}(\mathrm{D} \text {-glucose })_{\mathrm{m}}-\mathrm{H}\right]^{+}$ions $(\mathrm{m}=1$ or 2) together with (D-glucose) ${ }_{\mathrm{p}} \mathrm{H}^{+}$( $\mathrm{p}=1$ or 2$)$. These product ions further dissociate by elimination of $\mathrm{C}_{2} \mathrm{H}_{4} \mathrm{O}_{2}$, and one or several molecules of water, respectively.

The first process is not observed for ions $\mathrm{m} / \mathrm{z} 284$ and 374 . This result therefore suggests that $\mathrm{Pb}^{2+}$ ions might strongly interact with three molecules of D-glucose in the first coordination shell, and are surrounded by the other glucoses via intermolecular hydrogen bonds (outer coordination sphere). 
The charge separation process therefore constitutes the mechanism of formation of $\left[\mathrm{Pb}(\mathrm{D} \text {-glucose })_{\mathrm{m}}-\mathrm{H}\right]^{+}$ions (m=1or 2). It is the main dissociation channel, except for $\mathrm{m} / \mathrm{z} 644$. Moreover, since we do not detect protonated trimers or tetramers of D-glucose, ions $\mathrm{m} / \mathrm{z} 387$ and 567 certainly correspond to consecutive fragmentations from m/z 644, 554 (and 464 in the case of $\mathrm{m} / \mathrm{z}$ 387). Furthermore, additional MS/MS experiments have demonstrated that $\mathrm{m} / \mathrm{z} 387$ also originates from m/z 567 by loss of a D-glucose unit. One may also reasonably rule out the proton abstraction reaction (equation 2):

$$
\mathrm{Pb}^{2+}+\text { D-glucose } \longrightarrow[\mathrm{Pb}(\mathrm{D} \text {-glucose })-\mathrm{H}]^{+}+\mathrm{H}^{+}
$$

since $\mathrm{Pb}^{2+}$, if formed in the interface region, would certainly react dissociatively with the D-glucose molecule. Finally, a condensation reaction between lead(II) ions and anionic forms of $\mathrm{D}$-glucose can be also discarded, given the acidic $\mathrm{pH}$ of our solutions.

In summary, these data have demonstrated that the $[\mathrm{Pb}(\mathrm{D} \text {-glucose })-\mathrm{H}]^{+}$ion $(\mathrm{m} / \mathrm{z} 387)$ is the main complex observed under electrospray conditions and the paper will now focus on its structural characterization, by means of MS/MS experiments, labeled D-glucose and theoretical calculations.

Low-energy CID spectra of $[\mathbf{P b}(\mathrm{D} \text {-glucose })-\mathbf{H}]^{+}$ion $(\mathbf{m} / \mathbf{z} 387)$. The $[\mathrm{Pb}(\mathrm{D} \text {-glucose })-\mathrm{H}]^{+}$ species involving ${ }^{208} \mathrm{~Pb}(\mathrm{~m} / \mathrm{z}$ 387) was selected and allowed to dissociate upon collision with nitrogen. MS/MS spectra were systematically recorded at different collision energies between 1 to $30 \mathrm{eV}$ in the laboratory frame. This corresponds to center of mass collision energies $\left(\mathrm{E}_{\mathrm{cm}}\right)$ ranging from 0.07 and $2.02 \mathrm{eV}$ with nitrogen as target gas. The MS/MS spectrum obtained at $\mathrm{E}_{\mathrm{cm}}=0.9 \mathrm{eV}$ is presented in Figure $2 \mathrm{a}$. The $[\mathrm{Pb}(\mathrm{D} \text {-glucose })-\mathrm{H}]^{+}$ion essentially fragments according to cross-ring cleavages, characterized by elimination of $\mathrm{C}_{n} \mathrm{H}_{2 n} \mathrm{O}_{n}$ molecules ( $\mathrm{n}=2$ 4), and leading to 327, 297 and 267 ions. These dissociation processes have been already observed both under FAB and electrospray conditions for glucose derivatized with polyamines and cationized by various divalent transition metal ions such as $\mathrm{Ni}(\mathrm{II})^{42,43}$, $\mathrm{Zn}(\mathrm{II})^{43,44}, \mathrm{Cu}(\mathrm{II})^{43}$ or $\mathrm{Co}(\mathrm{II}) .{ }^{45}$ These fragmentations are also encountered when $\mathrm{Fe}(\mathrm{II})$ ions 
interact with underivatized D-glucose. ${ }^{46}$ Additional MS/MS spectra, including precursor ion scan mode and neutral loss experiments, result in the following fragmentation pattern (Scheme 2).

$<$ Scheme 2>

This shows that formation of 297 ions corresponds to a primary fragmentation, elimination of formaldehyde from m/z 327 being not observed. Elimination of $\mathrm{C}_{3} \mathrm{H}_{6} \mathrm{O}_{3}$ appears to be very minor as already observed with various metallic centers such as $\mathrm{Cu}$, $\mathrm{Ni}$ and $\mathrm{Co}^{45}$, or $\mathrm{Fe}^{46}$ Furthermore, m/z 267 ions arise either directly from the parent ion or via the intermediate formation of $\mathrm{m} / \mathrm{z} 327$ ions. The reactivity of $\mathrm{Pb}(\mathrm{II})$ ions also induces particular dissociation processes, corresponding to simultaneous elimination of $\mathrm{H}_{2} \mathrm{O}$ and $\mathrm{C}_{n} \mathrm{H}_{2 n} \mathrm{O}_{n}(n=2,3)$ neutrals. This has been observed before only in the case of copper cationization combined with use of ethylenediamine. ${ }^{43}$ In fact, precursor ion scan mode and neutral loss experiments suggest that the resulting ions, that is $\mathrm{m} / \mathrm{z} 309$ and 279 , are also generated via intermediate formation of m/z 327 and 297 ions, respectively. Unlike under FAB/metastable conditions ${ }^{12}$, dehydration from $[\mathrm{Pb}(\text { hexose })-\mathrm{H}]^{+}$ions is a very minor process. Finally, we do not detect any neutral fragments retaining the metal.

In order to propose reliable mechanisms for the cross-ring cleavages, and subsequently structures for $[\mathrm{Pb}(\mathrm{D} \text {-glucose })-\mathrm{H}]^{+}$ions, we undertook additional MS/MS experiments using both deoxy-D-glucoses and glucose labeled either by ${ }^{13} \mathrm{C}$ or deuterium. The resulting spectra are presented in Figure 2 and 3.

\section{Loss of $\mathrm{C}_{2} \mathrm{H}_{4} \mathrm{O}_{2}$.}

Elimination of $\mathrm{C}_{2} \mathrm{H}_{4} \mathrm{O}_{2}$ is the predominant process under $\mathrm{FAB} /$ metastable conditions. ${ }^{12}$ Though the ionization step is different, this suggest that this fragmentation requires a very small amount of energy to occur.

During a previous study ${ }^{13}$, use of 1-O-methyl-D-glucoses indicated that the anomeric center could be involved in the fragmentation, since loss of $\mathrm{C}_{2} \mathrm{H}_{4} \mathrm{O}_{2}$ was changed to $\mathrm{C}_{3} \mathrm{H}_{6} \mathrm{O}_{2}$ when a 
methoxyl group replaced the anomeric hydroxyl. If so, one may reasonably assume that the second carbon involved in $\mathrm{C}_{2} \mathrm{H}_{4} \mathrm{O}_{2}$ could correspond to $\mathrm{C}(2)$, insofar as elimination of $\mathrm{C}_{2} \mathrm{H}_{4} \mathrm{O}_{2}$ involving $\mathrm{C}(1)$ and not $\mathrm{C}(2)$ would require a considerable rearrangement during the dissociation. This is supported by the MS/MS spectrum of $[\mathrm{Pb}(2 \text {-deoxy-D-glucose })-\mathrm{H}]^{+}$ complex (Figure 2b) which is characterized by exclusive elimination of a $\mathrm{C}_{2} \mathrm{H}_{4} \mathrm{O}$ neutral $(\mathrm{m} / \mathrm{z}$ 327), whereas a loss of 60 mass units is still observed with 6-deoxy-D-glucose (m/z 311, Figure 2d). In summary, the experiments carried out with deoxy-D-glucoses are in favor of the elimination of $\mathrm{C}(1)$ and $\mathrm{C}(2)$ stereocenters. However, as nothing proves that glucose and deoxy glucoses interact with $\mathrm{Pb}^{2+}$ ions in the same way, we have undertaken an extensive labeling study. This study is illustrated by Figures $2 \mathrm{c}$ and 3 and the results are summarized in Table 2. As just mentioned, loss of a $\mathrm{C}_{2} \mathrm{H}_{4} \mathrm{O}_{2}$ unit without extensive rearrangement requires two adjacent carbon atoms to be expelled. This may correspond to four distinct cross-ring cleavages, implying either elimination of an ethen-1,2-diol unit $(\mathrm{HO}-\mathrm{CH}=\mathrm{CH}-\mathrm{OH})$ or loss of a glyoxal molecule $\mathrm{HOCH}_{2}-(\mathrm{CO}) \mathrm{H}$. First, we can remark that, whatever the labeled monosaccharide studied, elimination of $\mathrm{C}_{2} \mathrm{H}_{4} \mathrm{O}_{2}$ corresponds to a single peak in the spectra (Figure 2c and 3). This supports the assumption of adjacent carbons eliminated. Second, careful examination of Table 2 clearly demonstrates that the loss of $\mathrm{C}_{2} \mathrm{H}_{4} \mathrm{O}_{2}$ involves exclusively the elimination of the $\mathrm{C}(1)$ and $\mathrm{C}(2)$ stereocenters (Scheme 3), thus confirming the results obtained with deoxy-D-glucoses.

\section{$<$ Scheme3>}

This mechanism formally corresponds to ${ }^{0,2} \mathrm{~A}$ fragmentation according to the Domon and Costello convention. ${ }^{47}$ This result may also suggest that $\mathrm{Pb}^{2+}$ ions interact with the ring oxygen and one or several of the hydroxyl groups borne by carbon atoms 3,4 or 6 (Scheme 1) prior to fragmentation.

\section{Loss of $\mathrm{C}_{4} \mathrm{H}_{8} \mathrm{O}_{4}$.}


Elimination of $\mathrm{C}_{4} \mathrm{H}_{8} \mathrm{O}_{4}$ may also arise from four possible cross-ring cleavages. Nevertheless, a striking feature compared to the elimination of 60 mass units, is that this process generates two peaks in MS/MS spectra when using $6,6-{ }^{2} \mathrm{H}, 3-{ }^{13} \mathrm{C}-$, and $5-{ }^{13} \mathrm{C}-\mathrm{D}$-glucose (Figure 2c,3c-d, Table 2). Conversely, a single peak is observed when the isotope is located at position 1 or 2 , hence, demonstrating that $\mathrm{C}(1)$ and $\mathrm{C}(2)$ are systematically eliminated (Scheme3). In addition, examination of Table 2 shows that in a single-step process, these two atoms are expelled together with either $\mathrm{C}(3)+(\mathrm{C} 4)$ (the $\mathrm{Pb}^{2+}$ ion interacting with $\mathrm{CH}_{2} \mathrm{OH}$ ) or $\mathrm{C}(5)+\mathrm{C}(6)$ (with the metallic center bound to $\mathrm{OH}(3)$ and $\mathrm{OH}(4))$. Losses of $\mathrm{C}(2)$ and $\mathrm{C}(6)$ atoms are further confirmed by the MS/MS spectra obtained with 2-deoxy and 6-deoxy-D-glucose, respectively (elimination of $\mathrm{C}_{4} \mathrm{H}_{8} \mathrm{O}_{3}, 104$ Daltons). Our findings are not only in agreement with the intermediate formation of an ion $\mathrm{m} / \mathrm{z} 327$ by elimination of $\mathrm{C}(1) \mathrm{C}(2) \mathrm{H}_{4} \mathrm{O}_{2}$, but also clearly suggest that several structures, characterized by different coordination schemes, coexist in the gas-phase. This seems reasonable since the inter-ligand proton transfer associated to the charge separation process undergone by the $\left[\mathrm{Pb}(\mathrm{D} \text {-glucose })_{\mathrm{n}}\right]^{2+}$ ions should involve one of the hydroxylic protons, which are of comparable acidity. ${ }^{48}$

\section{Loss of $\mathrm{C}_{3} \mathrm{H}_{6} \mathrm{O}_{3}$}

As already noticed, elimination of $\mathrm{C}_{3} \mathrm{H}_{6} \mathrm{O}_{3}$ is a very minor process, while was not observed under FAB/MIKE conditions. ${ }^{12}$ For this particular fragmentation, the spectra obtained with labeled D-glucose are not conclusive. Loss of label observed on Figures 3a, 3b and 3c support the elimination of the $\mathrm{C}(1)-\mathrm{C}(2)-\mathrm{C}(3)$ chain. The spectrum obtained with $5-{ }^{13} \mathrm{C}$-D-glucose leads to the same conclusion (Table 2). However, as two peaks are observed in Figures 2c and 3c-d, formation of m/z 297 ions certainly arises from at least two mechanisms.

In summary, the data obtained during this study gave useful information concerning the two main cross-ring cleavages. Moreover, these results also indicate that gaseous $[\mathrm{Pb}(\mathrm{D} \text {-glucose })-\mathrm{H}]^{+}$ions may correspond to a mixture of several structures. 


\section{Computational study}

Our experiments have demonstrated that the main dissociation processes correspond to the elimination of $\mathrm{C}_{2} \mathrm{H}_{4} \mathrm{O}_{2}$ and $\mathrm{C}_{4} \mathrm{H}_{8} \mathrm{O}_{4}$. These fragmentations are already observed at the lowest collision energy $(0.07 \mathrm{eV})$, even with a very low pressure of nitrogen and a declustering potential set to 0 Volt (in fact the declustering potential has no effects on the MS/MS spectra observed). It is commonly admitted that electrospray is a "soft" ionization technique compared to other techniques such as LSIMS or MALDI, and that the amount of internal energy imparted to generated ions is the lowest of all mass spectrometric ionization techniques. ${ }^{49}$ Moreover precursor ions having a sufficient lifetime to reach the second quadrupole should be stable prior to collisional activation. So we have considered that the $[\mathrm{Pb}(\mathrm{D} \text {-glucose })-\mathrm{H}]^{+}$ions are stable species and that our experiments could be carried out in conjunction with ground state theoretical calculations. These calculations were performed in order to locate the best coordination sites, and subsequently, to propose possible mechanisms associated with the formation of $\mathrm{m} / \mathrm{z} 327$ and 267 ions.

In water, D-glucose involves almost exclusively ${ }^{50}$ (more than $99 \%$ ) an equilibrium between the two anomeric $\alpha$ and $\beta$ cyclic pyranose hemiacetals in their ${ }^{4} C_{1}$ chair conformations (as represented in Scheme 1). Consequently, we assumed in a first step that these pyranose rings remain intact during the electrospray process, and that $\mathrm{Pb}^{2+}$ ions interact initially with ${ }^{4} \mathrm{C}_{1}$ structures of both anomers. Given the fact that a deprotonation occurs and that metallic species may in principle attach to any of the electron-rich centers of D-glucose, including the hemiacetal oxygen, a considerable number of possible geometries should be considered. To restrict the number of structures investigated, we took into account the observations made during the studies of $\mathrm{Na}^{+} / \mathrm{D}$-glucose ${ }^{51}$ and $\mathrm{Cu}^{+} / \mathrm{D}$-glucose ${ }^{19}$ systems, by considering only bidentate or higher dentate modes, and by maximizing intramolecular hydrogen bondings in the complex. 
Given the size of this system, an extensive study consisting of PM3 semi-empirical calculations ${ }^{52}$ was carried out in a preliminary step. The most stable structures were then reoptimized at the B3LYP/6-31G(d,p) level. The results obtained by these two methods are in good agreement.

To describe the various structures, we adopted the nomenclature illustrated by scheme 4 .

\section{$<$ Scheme 4>}

We attributed a letter to each of the oxygen atoms. For example, a structure in which lead interacts with the anomeric center, the hydroxymethyl group $\left(\mathrm{CH}_{2} \mathrm{OH}\right)$ and the hemiacetal oxygen, is described by the formalism AEF. By convention, the first letter always refers to the deprotonated site.

To define the orientation of the hydroxyl groups, we have used a modified form of the nomenclature introduced by Cramer and Truhlar. ${ }^{53}$ This involves a six-letter descriptor, where the letters correspond to the orientation of the hydroxymethyl group $\left(\mathrm{CH}_{2} \mathrm{OH}\right)$, followed by that of the $\mathrm{C}(6), \mathrm{C}(4), \mathrm{C}(3), \mathrm{C}(2)$ and finally $\mathrm{C}(1)$ hydroxyl groups. The hydroxymethyl conformations are defined using the capital letters $\bar{G}, G$ and $T$, and the hydroxyl conformations by the letters $\overline{\mathrm{g}}$, $\mathrm{g}$ and $\mathrm{t}$, as reported previously. ${ }^{53}$ Each letter indicates whether the $\mathrm{H}-\mathrm{O}-\mathrm{C}(\mathrm{n})-\mathrm{C}(\mathrm{n}-1)$ dihedral angle (or the $\mathrm{O}(6)-\mathrm{C}(6)-\mathrm{C}(5)-\mathrm{O}$ dihedral for $\mathrm{CH}_{2} \mathrm{OH}$ ) is gauche(-) $[\overline{\mathrm{g}}, \overline{\mathrm{G}}]$, gauche $(+)[\mathrm{g}, \mathrm{G}]$ or trans $[\mathrm{t}, \mathrm{T}]$. According to the Cramer and Truhlar convention, gauche(-) means that a counterclockwise (viewed in the O-to-C(n) direction) rotation of the $\mathrm{OH}$ (or $\mathrm{CH}_{2} \mathrm{OH}$ ) of about $60^{\circ}$ is required to eclipse the bond $\mathrm{C}(\mathrm{n})-\mathrm{C}(\mathrm{n}-1)$ (or $\mathrm{C}(5)-\mathrm{O})$, while for gauche(+), the rotation is clockwise. With this convention, the ${ }^{4} \mathrm{C}_{1}$ chair conformation of $\alpha$-D-glucose depicted in scheme 4 is associated with the descriptor $\operatorname{Tgg} \bar{g} \bar{g} g$. Finally, the letter x characterizes the deprotonated site, as introduced by Mulroney et $a .^{48}$

B3LYP total and relative energies of the different cyclic structures are summarized in Table 3. For some of them, relevant bond lengths are given in Figures 4 and 5 (for $\alpha$ and $\beta$ anomers, 
respectively). Detailed geometries as well as cartesian coordinates of the various structures studied at the B3LYP level are given in the supporting information S1.

\section{Cyclic forms of $[\mathrm{Pb}(\mathrm{D} \text {-glucose })-\mathrm{H}]^{+}$ions.}

First, from Table 3, we can see that for both anomers and whatever the ring conformation adopted, the relative energy differences between the various geometries are small (less than $52 \mathrm{~kJ} / \mathrm{mol}$ ), and do not vary significantly with the level of calculation. This is in favor of a mixture of several structures in the gas-phase. This also suggests that the various fragmentation pathways observed upon collision may involve different initial conformations of the complex. Secondly, examination of Table 3 clearly indicates that the most stable ${ }^{4} C_{1}$ structures are characterized by a formal deprotonation of the hydroxymethyl function $\left(\mathrm{CH}_{2} \mathrm{OH}, \mathbf{E}\right)$, and additional interaction with either adjacent hydroxyl group (D) or hemiacetal oxygen $(\mathbf{F})$. It turns out that it corresponds to the deprotonation of the least acidic hydroxyl. ${ }^{48}$ These coordination schemes are also in agreement with the specific elimination of $\mathrm{C}(1)$ and $\mathrm{C}(2)$ centers associated with the formation of the $\mathrm{m} / \mathrm{z} 327$ ion.

Globally, the cation stability appears to be governed by the nature of the deprotonated site. In the particular case of ${ }^{4} \mathrm{C}_{1}$ conformations, the structures are essentially bidentate, and there are no evident correlations between the stability and the number of intramolecular hydrogen bonds. Moreover, concerning the $\mathbf{B C}, \mathbf{C D}$ and $\mathbf{D E}$ structures, we can see as the consequence of the exo-anomeric effect ${ }^{54}$, that the anomeric hydroxyl remains preferentially in the $\mathrm{g}$ (anomer $\alpha$ ) or $\bar{g}$ (anomer $\beta$ ) orientation (Figures 4 and 5), instead of participating in a cooperative hydrogen bonding scheme ( $\mathrm{t}$ orientation). This effect is more pronounced as the deprotonated site gets closer to the anomeric position.

Interactions between metals and monosaccharides have been widely studied in aqueous solutions ${ }^{5}$, and NMR studies revealed that metal binding to simple carbohydrates according to tridentate modes are particularly favorable, especially when the monosaccharide has an axialequatorial-axial or axial-axial-axial sequence of $\mathrm{OH}$ groups. As this sequence is not 
encountered for ${ }^{4} \mathrm{C}_{1}$ forms, we also considered seven additional ring conformations (one chair and six boats), presented in Scheme 4, in order to obtain axial hydroxyl groups. The results presented in Table 3 show that, once again, the most stable geometries are those involving a deprotonated hydroxymethyl group. With these seven ring conformations, tricoordinations are more easily obtained. Furthermore, for both anomers, the most stable cyclic structure is characterized by a ${ }^{0,3} \mathrm{~B}$ boat form, and a tridentate interaction involving the deprotonated $\mathrm{CH}_{2} \mathrm{OH}$ group $(\mathbf{E})$, the hemiacetal oxygen $(\mathbf{F})$ and the hydroxyl $(\mathbf{C})$ borne by the carbon $\mathrm{C}(3)$. This particular coordination scheme $\left({ }^{\mathbf{0 , 3}} \mathbf{B} \_\mathbf{E F C}\right)$ had also been also found to be the most favorable in the case of cationization of D-glucose by sodium ions. ${ }^{51}$ Our calculations also emphasize the influence of intramolecular hydrogen bonds on the stability of several boat conformations. Thus, we failed in locating stable $\boldsymbol{\alpha}_{-}{ }^{\mathbf{1}, \mathbf{4}} \mathbf{B}$ and $\boldsymbol{\beta}_{-}{ }^{\mathbf{1 , 4}} \mathbf{B}$ forms. These geometries indeed collapse during the optimization step into $\boldsymbol{\alpha}_{-} \mathbf{B}_{\mathbf{0}, \mathbf{3}}$ and $\boldsymbol{\beta}_{-}{ }^{\mathbf{2 , 5}} \mathbf{B}$ conformations, respectively, promoted by hydrogen bonds strengthening. More generally, all the boat forms obtained except ${ }^{\mathrm{O}, 3} \mathrm{~B}$ geometries, can be viewed as skew forms, that are intermediate between two boat conformations.

To give a picture of the distribution of charge within the $[\mathrm{Pb}(\mathrm{D} \text {-glucose })-\mathrm{H}]^{+}$species, we have carried out a natural population analysis (NPA) at the B3LYP/6-31G(d,p) level by means of the NBO program for all the structures investigated. ${ }^{55}$ NPA charges show a transfer of electrons to the lead from the glucose moiety, the local charge on $\mathrm{Pb}$ ranging from 1.44 to 1.49. This value is smaller that the local charge determined for $\left[\mathrm{Pb}\left(\mathrm{H}_{2} \mathrm{O}\right)_{4}\right]^{2+}$ ions $(1.76-1.78)^{38,56}$, thus indicating a greater degree of electron transfer. This analysis also reveals a slight increase of the negative charge for the interacting oxygen, accompanied by the lengthening of the corresponding C-O bonds.

Furthermore, examination of the natural bond orbitals (NBO) shows that the $\mathrm{Pb}$ (II) lone pair is predominantly $6 \mathrm{~s}$, but is slightly polarized by a small $6 \mathrm{p}$ contribution, ranging from 3.4 to 4.7 \%. This feature is characterictic of hemi-directed structures, as already noticed by Bock 
and co-workers in their study on tetravalent lead(II) complexes ${ }^{56}$, but is also the signature of ionic bonds. The $[\mathrm{Pb}(\mathrm{D} \text {-glucose })-\mathrm{H}]^{+}$structures would in fact correspond to $\left[\mathrm{Pb}^{2+}\right.$-alkoxy anion] systems. Nevertheless, natural electron configuration analysis indicates that the electron transfer is mostly in the $6 p$ orbitals (typical values being : $6 s[1.92]$ $\left.6 \mathrm{p}[0.61] \mathrm{sp}^{0.32}\right)$. The value of 0.32 for $\mathrm{Pb}(\mathrm{II}) \mathrm{sp}$ hybridization, is greater than the value obtained for the $\left[\mathrm{Pb}\left(\mathrm{H}_{2} \mathrm{O}\right)_{4}\right]^{2+}$ ionic complex ${ }^{56}(0.16)$, thus suggesting a certain degree of covalency in the $\mathrm{Pb}-\mathrm{O}$ bond.

\section{Mechanisms of elimination of $\mathrm{C}_{2} \mathrm{H}_{4} \mathrm{O}_{2}$ and $\mathrm{C}_{4} \mathrm{H}_{8} \mathrm{O}_{4}$ molecules.}

The electron transfer from D-glucose to lead cation induces significant geometrical

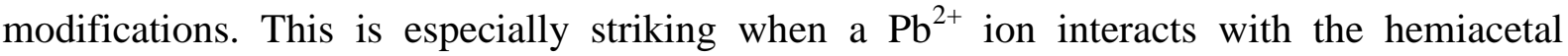
oxygen (EF structures), as illustrated by Figures 4 and 5. To discuss this particular point, we have included in these figures, the geometry of three neutral D-glucose conformers, obtained at the same level of calculations. Thus, comparison for example, between $\alpha \_g l c 2$ and $\boldsymbol{\alpha}_{-}{ }^{4} \mathbf{C}_{1} \_\mathbf{E F}$ structures demonstrates that interaction with $\mathrm{a} \mathrm{Pb}^{2+}$ ion induces an important activation of the $\mathrm{C}(1)-\mathrm{O}(5)$ (lengthening by $23 \%$ ). This finding is in agreement with the experimental observation of cross-ring cleavages (loss of $\mathrm{C}_{n} \mathrm{H}_{2 n} \mathrm{O}_{n}$ ). Consequently, the EFlike complexes may correspond to the precursor ions, which, upon collision, dissociate according to cross-ring cleavages. The $\mathrm{C}(1)-\mathrm{O}(5)$ bond cleavage promoted by the metallic center may therefore constitute the first step of the mechanisms of dissociation proposed in Scheme 5, which also account for the details deduced from the isotope labeling experiments.

\section{$<$ Scheme 5>}

The resulting acyclic form may undergo a proton transfer, followed by a McLafferty rearrangement, to give rise to the ion $\mathrm{m} / \mathrm{z} 327$ by loss of the $\mathrm{C}(1)$ and $\mathrm{C}(2)$ carbons. In turn, this ion expels a second $\mathrm{C}_{2} \mathrm{H}_{4} \mathrm{O}_{2}$ (including $\mathrm{C}(3)$ and $\mathrm{C}(4)$ atoms) to generate $\mathrm{m} / \mathrm{z} 267$ ions. These latter species may also come directly from m/z 387 as evidenced experimentally. 
We have also demonstrated that $\mathrm{m} / \mathrm{z} 267$ ions also arise from the elimination of the $\mathrm{C}(1)$, $\mathrm{C}(2), \mathrm{C}(5)$ and $\mathrm{C}(6)$ carbons. Thus, this particular fragmentation could involve a precursor $\mathrm{m} / \mathrm{z} 387$ ion in which the metallic center is bound either to $\mathrm{C}$ or D hydroxyl groups (Scheme 5). Indeed, we can see from Figures 4 and 5, that structures $\mathbf{C D}$ and DC induce lengthening of the $\mathrm{C}(2)-\mathrm{C}(3)$ and $\mathrm{C}(4)-\mathrm{C}(5)$ bonds, respectively, and therefore may correspond to the precursor ions. On the other hand, this fragmentation may also proceed in two steps from a EF-like coordinated species, via internal reorganization within the $\mathrm{m} / \mathrm{z} 327$ ion, as depicted in Scheme 5 .

\section{Opened forms of $[\mathrm{Pb}(D \text {-glucose })-H]^{+}$ions.}

Cross-ring cleavages are the main fragmentations observed upon collision with nitrogen. Furthermore, the $\mathrm{Pb}^{2+}$ ion, when bound to the hydroxymethyl group and interacting with the hemiacetal oxygen, strongly activate not only the $\mathrm{C}(1)-\mathrm{O}(5)$ bond, but also the $\mathrm{C}(5)-\mathrm{O}(5)$ bond. These two observations raise the following question : can $\mathrm{Pb}^{2+}$ interactions give rise to stable opened $[\mathrm{Pb}(\mathrm{D} \text {-glucose })-\mathrm{H}]^{+}$structures ? To address this question, we considered three modes of cleavage, as presented in Scheme 6. These three modes involve either C(1)-O(5) (open1 and open2) or C(5)-O(5) (open3) bond cleavage, associated with 1,3H shift from $\mathrm{C}(5)$ to $\mathrm{C}(1), \mathrm{O}(1)$ to $\mathrm{O}(5)$, and $\mathrm{C}(1)$ to $\mathrm{C}(5)$, respectively.

\section{$<$ Scheme 6>}

Moreover, the second mode also corresponds to interaction between lead(II) ions and the natural open keto form of glucose. We focused on the interactions involving the terminal oxygens, which, in principle, should confer the most stability. The relative energies of the different structures considered are gathered in Table 4, and the two most stable geometries for each opening mode are given in Figure 6. Due to the greater flexibility of the carbon chain, tetradentate geometries are easily obtained. The results deduced from NBO analysis are similar to those of cyclic forms. However, unlike the cyclic complexes, $\mathrm{Pb}^{2+}$ interaction with the deprotonated hydroxymethyl group is not favored. The distance between the metallic 
center and the deprotonated hydroxyl is slightly longer $(2.100-2.150 \AA)$ than for cyclic forms (typically $2.070 \AA$ A). For the sake of comparison, Table 4 also includes the most stable cyclic geometry ( $\left.\boldsymbol{\beta}_{-}{ }^{\mathbf{0}, 3} \mathbf{B} \_\mathbf{E F C}\right)$. We can see that the first two modes of cleavage lead to structures that fall in the same energy range as the cyclic complexes. On the other hand, cleavage of the $\mathrm{C}(5)-\mathrm{O}(5)$ generates acyclic complexes that are considerably more stable (by more than 100 $\mathrm{kJ} / \mathrm{mol}$ for structure open3_BDEF) than the cyclic forms. This kind of situation has already been encountered for the $\mathrm{Cu}^{+} / \mathrm{D}$-glucose system. ${ }^{19}$ Furthermore, as the most stable cyclic forms are characterized by a very strong $\mathrm{C}(5)-\mathrm{O}(5)$ bond activation, one may reasonably assume, that these forms, competitively with cross-ring cleavage, may collapse to open 3 complexes provided they have a sufficient amount of internal energy to achieve the activation barriers associated with $1,3 \mathrm{H}$ shift. Nevertheless, the other opened structures, rigorously, cannot be discarded.

\section{Conclusion}

The present study has shown that under electrospray conditions, gaseous lead(II) ions react with $\mathrm{D}$-glucose to form both $\left[\mathrm{Pb}(\mathrm{D} \text {-glucose })_{\mathrm{m}}-\mathrm{H}\right]^{+}$and $\left[\mathrm{Pb}(\mathrm{D} \text {-glucose })_{\mathrm{n}}\right]^{2+}$ complexes. MS/MS experiments on the most abundant complex, $[\mathrm{Pb}(\mathrm{D} \text {-glucose })-\mathrm{H}]^{+}(\mathrm{m} / \mathrm{z} 387)$ show that this ion essentially dissociates by cross-ring cleavages (loss of $\mathrm{C}_{2} \mathrm{H}_{4} \mathrm{O}_{2}$ and $\mathrm{C}_{4} \mathrm{H}_{8} \mathrm{O}_{4}$ neutrals). According to labeling experiments, the first involves specific elimination of $\mathrm{C}(1)$ and $\mathrm{C}(2)$ centers. The second corresponds to at least two distinct fragmentations and suggests that $\mathrm{m} / \mathrm{z} 387$ ion may correspond to a mixture of several structures. This is supported by our theoretical study carried out on both pyranosic anomers. The most favorable $\mathrm{Pb}^{2+} / \mathrm{D}$-glucopyranose association, involving the metallic center attached to the deprotonated hydroxymethyl group and interacting with the hemiacetal oxygen is characterized by strongly activated C-O ring bonds. This not only accounts for the fragmentation observed upon collision, but also suggests that pyranosic complexes may also collapse to give the energetically favored acyclic structures. 


\section{Acknowledgements}

The authors would like to thank the Institut du Développement et des Ressources en Informatique Scientifique (IDRIS, CNRS) for computational time. Omicron Biochemicals is acknowledged for purchasing facilities. The authors are also indebted to the "Conseil General d'Ile de France" for financial support. Finally we would like to thank Pr. O. Mó, and M. Yáñez for helpful discussion.

\section{Supporting information available}

B3LYP/6-31G(d,p) geometry and cartesian coordinates of the different structures investigated during the computational study are provided (52 pages). 


\section{References and notes}

1 Rhue, R. D.; Mansell, R. S.; Ou, L. T.; Cox, R.; Tang, S. R.; Ouyang, Y. Crit. Rev. Environ. Control 1992, 22, 169.

2 Łobiñski, R.; Adams, F. C. Anal. Chim. Acta, 1992, 262, 285.

3 Gorecki, T.; Pawliszyn, J. Anal. Chem. 1996, 68, 3008.

4. Uhlenbeck, O. C.; Pan, T. Nature, 1992, 358, 560.

5. Whitfield, D. M.; Stojkovski, S.; Sarkar, B. Coordin. Chem. Rev. 1993, 122, 171.

6. Yano, S.; Otsuka, M. in Metal Ions in Biological Systems; Ed. by A. Sigel and H. Sigel; Marcel Dekker: New-York, US, 1996;Vol. 32, pp. 28.

7. Ekström, L. G.; Olin, Å. Acta Chem. Scand. A 1977, 31, 838.

8. Coccioli, F.; Vicedomini, M. J. Inorg. Nucl. Chem. 1978, 40, 2103.

9. Vesala, A.; Lönnberg, H.; Käppi, R.; Arpalahti J. Carbohydr. Res. 1982, 102, 312.

10. Mihalick, J. E.; Griffiths III, W. P.; Muten, J. E.; Olson, T. A.; Hein, J. B. J. Soln. Chem. 1999, 28, 1019.

11. Salpin, J-Y.; Tortajada, J. Adv. Mass Spectrom. 2001, 15, 735.

12. Salpin, J-Y.; Tortajada, J.; Boutreau, L.; Haldys, V. Eur. J. Mass Spectrom. 2001, 7, 321.

13. Salpin, J-Y.; Tortajada, J. J. Mass Spectrom. 2002, 37, 379.

14. Gaussian 98, Revision A.7, Frisch, M. J.; Trucks, G. W.; Schlegel, H. B.; Scuseria, G. E.; Robb, M. A.; Cheeseman, J. R.; Zakrzewski, V. G.; Montgomery Jr., J. A.; Stratmann, R. E.; Burant, J. C.; Dapprich, S.; Millam, J. M.; Daniels, A. D.; Kudin, K. N.; Strain, M. C.; Farkas, O.; Tomasi, J.; Barone, V.; Cossi, M.; Cammi, R.; Mennucci, B.; Pomelli, C.; Adamo, C.; Clifford, S.; Ochterski, J.; Petersson, G. A.; Ayala, P. Y.; Cui, Q.; Morokuma, K.; Malick, D. K.; Rabuck, A. D.; Raghavachari, K.; Foresman, J. B.; Cioslowski, J.; Ortiz, J. V.; Baboul, A. G.; Stefanov, B. B.; Liu, G.; Liashenko, A.; Piskorz, P.; Komaromi, I.; Gomperts, R.; Martin, R. L.; Fox, D. J.; Keith, T.; Al-Laham, M. A.; Peng, C. Y.; Nanayakkara, A.; Gonzalez, C.; Challacombe, M.; Gill, P. M. W.; Johnson, B.; Chen, W.; Wong, M. W.; Andres, J. L.; Gonzalez, C.; Head-Gordon, M.; Replogle, E. S.; and Pople, J. A. Gaussian, Inc., Pittsburgh PA, 1998.

15. Becke, A. D. J. Chem. Phys. 1993, 98, 5648. 
16. Lee, C.; Yang, W.; Parr, R. G. Phys. Rev. B Condens. Matter 1988, 37, 785.

17. Hoyau, S.; Ohanessian, G. Chem. Phys. Lett. 1995, 246, 40.

18. Kemper, P. R.; Weis, P.; Bowers, M. T.; Maitre, P. J. Am. Chem. Soc. 1998, 120, 13494.

19. Alcamí, M.; Luna, A.; Mó, O.; Yáñez M.; Boutreau, L.; Tortajada, J. J. Phys. Chem. A 2002, 106, 2641.

20. González, L.; Mó, O.; Yáñez, M. J. Comput. Chem. 1997, 18, 1124.

21. González, L.; Mó, O.; Yáñez, M. J. Phys. Chem. A 1997, 101, 9710.

22. González, L.; Mó, O.; Yáñez, M. J. Chem. Phys. 1998, 109, 139.

23. Küchle, W.; Dolg, M.; Stoll, H.; Preuss, H. Mol. Phys. 1991, 6, 1245.

24 Salpin, J-Y.; Tortajada, J.; Alcamí, M.; Luna, A.; Mó, O.; Yáñez M. manuscript in preparation

25 González, A. I .; Mó, O.; Yáñez, M. J. Chem. Phys. 2000, 112, 2258.

26. Vukomanovic, D.; Stone, J. A. Int. J. Mass Spectrom. 2000, 202, 251.

27. Jayaweera, P.; Blades, A. T.; Ikonomou, M. G.; Kebarle, P. J. Am. Chem. Soc. 1990, 112, 2452.

28. Blades, A. T.; Jayaweera, P.; Ikonomou, M. G.; Kebarle, P. Int. J. Mass Spectrom. Ion Processes 1990, 101, 325.

29. Blades, A. T.; Jayaweera, P.; Ikonomou, M. G.; Kebarle, P. Int. J. Mass Spectrom. Ion Processes 1990, 102, 251.

30. Cheng, Z. L.; Siu, K. W. M.; Guevremont, R.; Berman, S. S. J. Am. Soc. Mass Spectrom. 1992, 3, 281.

31. Peschke, M.; Blades, A. T.; Kebarle, P. J. Phys. Chem. A 1998, 102, 9978.

32. Rodriguez, S. E.; Jockusch, R. A.; Williams, E. R. J. Am. Chem. Soc. 1999, 121, 8898.

33. Peschke, M.; Blades, A. T.; Kebarle, P. J. Am. Chem. Soc. 2000, 122, 10440.

34 Beyer, M.; Williams, E. R.; Bondybey, V. E. J. Am. Chem. Soc. 1999, 121, 1565.

35. Cotton, F. A.; Wilkinson, G.; Murillo, C. A.; Bochmann, M. Advanced Inorganic Chemistry; $6^{\text {th }}$ Ed.; Wiley-Interscience: New-York, 1999.

36 Shvarstburg, A.; Siu, K. W. M. J. Am. Chem. Soc. 2001, 123, 10071.

37. Nimal Perera W.; Hefter, G.; Sipos, P. M. Inorg. Chem. 2001, 40, 3974 and reference 37 cited therein. 
38 Akibo-Betts, G.; Barran, P. E.; Puskar, L.; Duncombe, B.; Cox, H.; Stace, A. J. J. Am. Chem. Soc. 2002, 124, 9257.

39 Pearson, R. G. Chem. Ber. 1967, 3, 103.

40. Fura, A.; Leary, J. A. Anal. Chem. 1993, 65, 2805.

41 Carlesso, V.; Afonso, C.; Fournier, F.; Tabet, J. C. Int. J. Mass Spectrom. 2002, 219, 559.

42. Smith, G.; Leary, J.A. Journal of the American Chemical Society. 1998, 120, 13046.

43. Smith G., Kaffashan, A.; Leary, J.A. Int. J. Mass Spectrom. 1999, 182/183, 299.

44. Gaucher, S. P.; Leary, J. A. Anal. Chem. 1998, 70, 3009.

45. Gaucher, S. P.; Leary, J. A. Int. J. Mass Spectrom. 2000, 197, 139.

46. Carlesso, V.; Fournier, F.; Tabet, J. C. Eur. J. Mass Spectrom. 2000, 6, 421.

47. Domon, B.; Costello, C. E. Glycoconjugate J. 1988, 5, 397.

48 Mulroney, B.; Peel, J. B.; Traeger, J. C. J. Mass Spectrom. 1999, 34, 544.

49 Cole R.B. J. Mass Spectrom. 2000, 35, 763.

50 Collins, P.; Ferrier, R. Monosaccharides: their chemistry and their role in natural products; Ed. John Wiley and Sons: Chichester, 1995.

51 Cerda, B. A., Wesdemiotis, C. Int. J. Mass Spectrom. 1999, 189, 189.

52 (a) Stewart, J. J. P. J. Comput. Chem. 1989, 10, 209. (b) Hyperchem ${ }^{\circledR}$ Release 6.01 for Windows ${ }^{\circledR}$, Hypercube, Inc. (1999).

53. Cramer, C. J.; Truhlar, D. G. J. Am. Chem. Soc. 1993, 115, 5745.

54 Lemieux, R. U.; Pavia, A. A.; Martin, J. C.; Watanabe, K. A. Can. J. Chem. 1969, 47, 4427.

55 Glendening, E. D.; Reed, A. E.; Weinhold, F. NBO version 3.1.

56. Shimony-Livny, L.; Glusker, J. P.; Bock, C. W. Inorg. Chem. 1998, 37, 853. 